\title{
ANÁlise dA USINABILIDADE POR PENETRAÇÃo PERPENDICULAR E OBLÍQUA DE ROSCAS EXTERNAS EM LIGA DE ALUMÍNIO 6351-T6
}

\author{
Ronaldo dos Santos Brito*, Daniel Iwao Suyama.
}

\section{Resumo}

Para se produzir uma rosca, é necessário definir uma operação. As operações mais comuns para roscamento externo são: a penetração oblíqua e a penetração perpendicular, as quais se diferenciam, principalmente, pelo sentido de deslocamento da ferramenta em relação à peça. O objetivo do projeto é apresentar dados experimentais técnicos que padronizem a escolha das operações em ligas de alumínio 6351-T6, possibilitando vantagens econômicas e produtivas para empresas que pratiquem estas operações frequentemente. O intuito final é apresentar, para cada medida de rosca analisada, a melhor opção de operação. Para isso, utilizou-se ensaios em laboratório, com a verificação de qualidade e tempo de produtividade para a usinagem de rosca externa de diversas medidas e em ambas operações. Dessa forma, notou-se que, no geral, o ciclo de produção da penetração oblíqua é mais lenta que a perpendicular e que os passos são proporcionais ao tempo. A qualidade de ambas ficou abaixo das referências.

Palavras-chave: Roscamento, Operações, Padronização.

\section{Introdução}

Dentre inúmeros procedimentos possíveis no processo de usinagem, o roscamento externo é um dos mais utilizados quando se deseja obter uma rosca externa ${ }^{1}$. Este procedimento pode variar de acordo com o tipo de rosca externa e o material que será torneado.

Basicamente, existem duas operações possíveis: o torneamento de roscas externas por penetração perpendicular - mais indicada para roscas menores e materiais mais dúcteis -, e a penetração oblíqua, utilizada em roscas maiores e materiais mais duros ${ }^{3}$. No geral, não há estudos científicos mostrando quando é mais vantajoso utilizar uma ou outra operação, o que pode gerar perda de recursos e de produtividade.
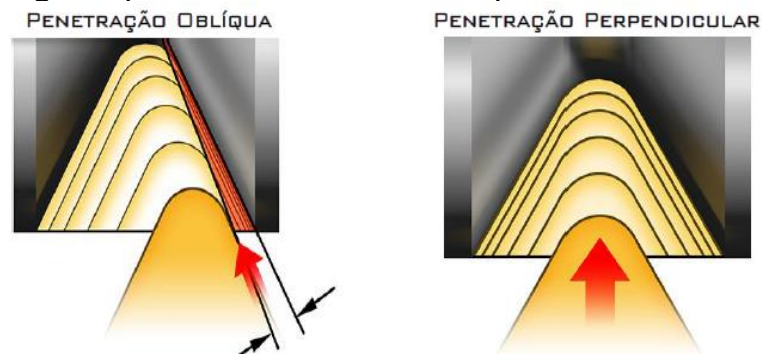

Figura 1. Representação dos dois tipos de penetração. ${ }^{3}$ O trabalho de pesquisa visa apresentar dados experimentais técnicos das duas operações para roscamento externo em liga de alumínio 6351-T6², afim de compará-las quanto à qualidade e produtividade para esta classe de material. O intuito final, portanto, é organizar os dados experimentais coletados, buscando uma possível padronização das escolhas de operações de roscamento nestas condições.

\section{Resultados e Discussão}

Para a realização do estudo foram torneadas, em torno CNC, roscas de diâmetros variando de $10 \mathrm{~mm}$ até $60 \mathrm{~mm}$, com diferentes passos. Foi produzida uma peça para cada operação de estudo e todos os outros fatores foram mantidos constantes ${ }^{1}$ (máquina, material da peça, comprimento da rosca, ferramenta de corte, óleo refrigerante, etc.). Desse modo, as comparações foram feitas a partir da análise do tempo do processo, utilizando um cronômetro. Para analisar a qualidade de cada rosca usinada, utilizou-se um projetor de perfil.
As análises dos tempos de cada processo mostraram que a penetração oblíqua, no geral, requer mais tempo de ciclo do que a perpendicular. Além disso, pôde-se observar que o passo da rosca e o tempo são inversamente proporcionas.

Gráfico 1. Tempo de cada operação em função da medida. PRODUTIVIDADE DO CICLO DE CADA PROCESSO

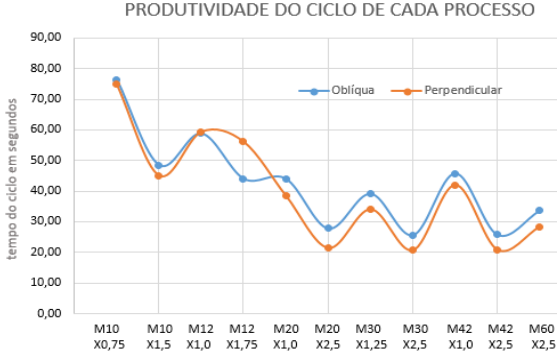

Em relação a qualidade, notou-se visualmente que as roscas de mesma medida e passo, feitas em operações diferentes, não se encaixavam perfeitamente. Quando colocadas no projetor de perfil, foi possível notar as diferenças que haviam entre ambas e em relação às medidas teóricas. Além disso, analisando o nível de acabamento das peças, notou-se que o vale de cada filete não estava igual para as duas operações.

\section{Conclusões}

Concluiu-se que, no geral, as roscas por penetração perpendicular são mais rápidas de se fazer, mas, no entanto, suas medidas se distanciam da referência teórica utilizada. Desse modo, mais estudos com roscas maiores e menores devem ser feitos para uma conclusão mais aprofundada.

\section{Agradecimentos}

O presente trabalho foi realizado com apoio do Conselho Nacional de Desenvolvimento Científico e Tecnológico (CNPq). Agradeço o suporte da FCA-Unicamp, e a toda equipe do Senai Luiz Varga de Limeira pelo apoio prático.

${ }^{1}$ FERRARESI, D. Fundamentos da Usinagem dos Metais. $1^{\mathrm{a}}$ ed.; São Paulo: Editora Edgard Blücher, 1977.

2 WEINGAERTNER, W.L.; Schroeter, R.B. Tecnologia de usinagem do alumínio e suas ligas. 2. ed. São Paulo: Alcan - Alumínio do Brasil, 1991.

3 SANDVIK COROMANT. Torneamento de Roscas: Guia de Aplicação. $2018 . \quad$ Disponível em <https://www.sandvik.coromant.com/SiteCollectionDocuments/downloads/glob al/technical guides/en-gb/C-2920-031.pdf>. Acesso em: 04 mar. 2018. 